\title{
Distal Fibular Interosseous Osteochondroma Producing Pressure Effects on the Tibia: A case report
}

\author{
by Asif Sultan ${ }^{1 凶}$, Iqbal Wani ${ }^{1}$, Mubashir Maqbool Wani ${ }^{\circledR}$, Manzoor Ahmad Halwai ${ }^{1}$, Arshid Bashir ${ }^{1}$, \\ Bashir Ahmad Mir ${ }^{1}$
}

The Foot and Ankle Online Journal 3 (10): 3

Osteochondroma are believed to be most common benign tumors accounting for 36\% to $41 \%$ of all such tumors. We report a rare occurrence of such a tumor in distal interosseous space of leg. In our case osteochondroma arising from distal fibula invaded the interosseous space and produced pressure effects on tibia. We believe this may be the first reported case of distal fibular osteochondroma producing pressure effects on the tibia. The tumor was excised using a transfibular approach and osteotomy site fixed with a semitubular plate.

Key Words: Osteochondroma, interosseous space, pressure effects, transfibular approach.

Published: October, 2010

This is an Open Access article distributed under the terms of the Creative Commons Attribution License. It permits unrestricted use, distribution, and reproduction in any medium, provided the original work is properly cited. (The Foot and Ankle Online Journal (www.faoj.org)

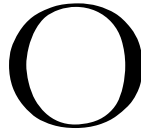
steochondromas are believed to be the most common benign bone tumors accounting for $36 \%$ to $41 \%$ of all such tumors. ${ }^{1}$ The growth of osteochondroma usually parallels that of the patient and usually ceases when skeletal maturity is reached. ${ }^{2}$ After an extensive literature search, there are few cases reported which mention an osteochondroma arising from distal tibia laterally and invading the interosseous space and producing pressure effects on fibula. ${ }^{3,4}$ Osteochondroma arising from distal fibula along medial aspect and producing pressure effects on tibia in a skeletally mature patient does not appear to be mentioned anywhere in the literature.
Address correspondence to: Asif Sultan. Government hospital for bone and joint surgery, Barzullah, Srinagar, India 190005

Email-drasifsultan@yahoo.com

${ }^{1}$ Government hospital for bone and joint surgery, Barzullah, Srinagar, India 190005.
We present a case of a patient who reported pain to the right leg anteriorly and distally with minimal swelling. This subsequently turned out to be a benign osteochondroma arising from fibula and producing pressure effects on tibia. The tumor was excised through a transfibular approach and the patient was symptom free after one and a half year follow up.

\section{Case Report}

A 22 year-old male Asian Indian in origin presented to us with pain right leg. The pain was located distally and anteriorly and was associated with minimal hard to appreciate swelling. After taking a detailed history and examination it became clear that the patient had been symptomatic for about one year and was being treated by the general practitioner. Symptoms included increase in pain on weight bearing to the affected limb. 


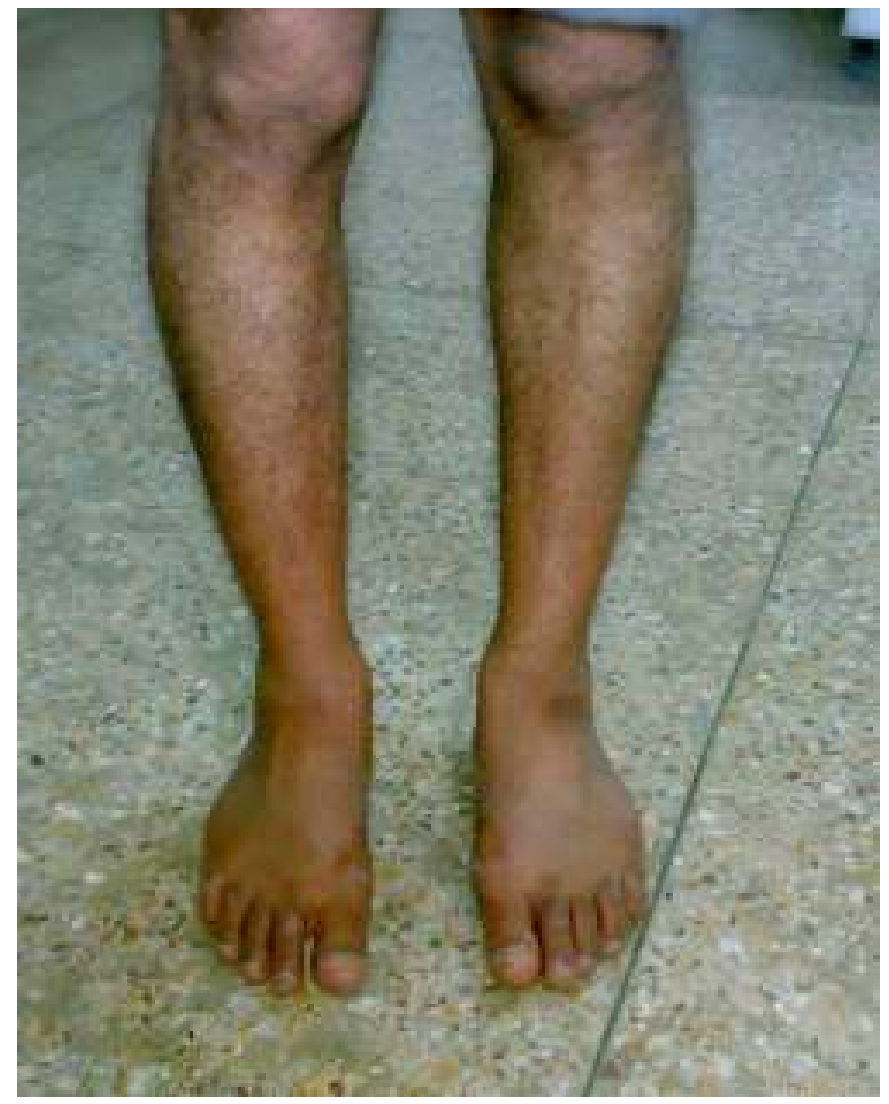

Figure 1 Clinical photograph with hard to appreciate swelling on right side.

The pain progressed to a more continuous intensity and even persisting during night and rest. In comparison to the contralateral limb, the affected side seemed to be slightly more swollen. (Fig. 1) There was tenderness at the distal interosseous space. Temperature was normal. All the hematological investigations were normal. A plain and digital radiograph was ordered which showed a bony swelling arising from distal fibula and expanding into the interosseous space and communicating with the lateral aspect of tibia. (Figs. 2 and 3) A computed tomography (CT) scan was done which confirmed the diagnosis and also revealed that the tumor is producing pressure effects on tibia. (Fig. 4) By using a transfibular approach, the tumor mass was excised (Fig. 5) and sent to histopathology. The scalloping of lateral aspect of tibia was confirmed.

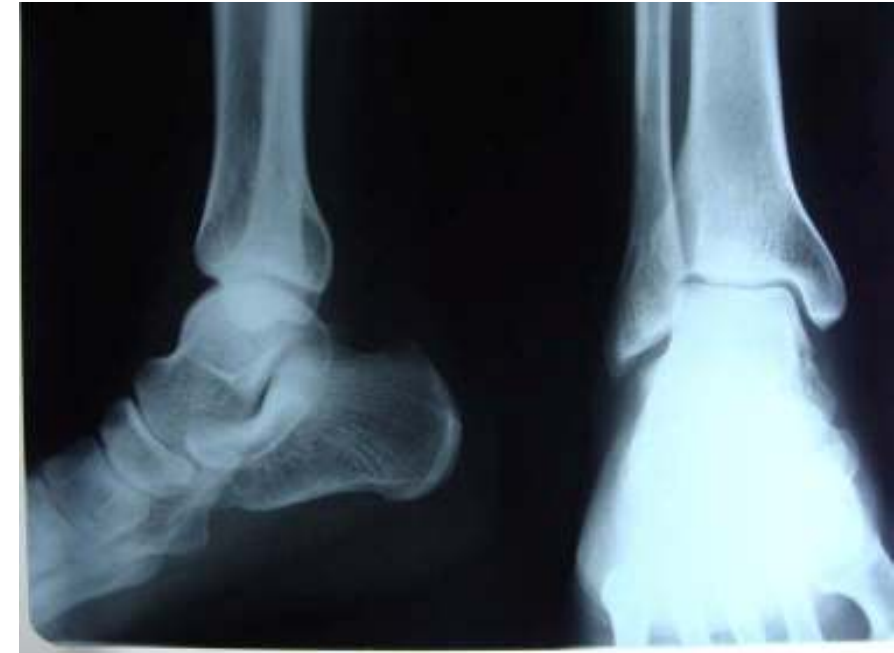

Figure 2 Plain radiograph showing an anteroposterior and lateral view of the right ankle.

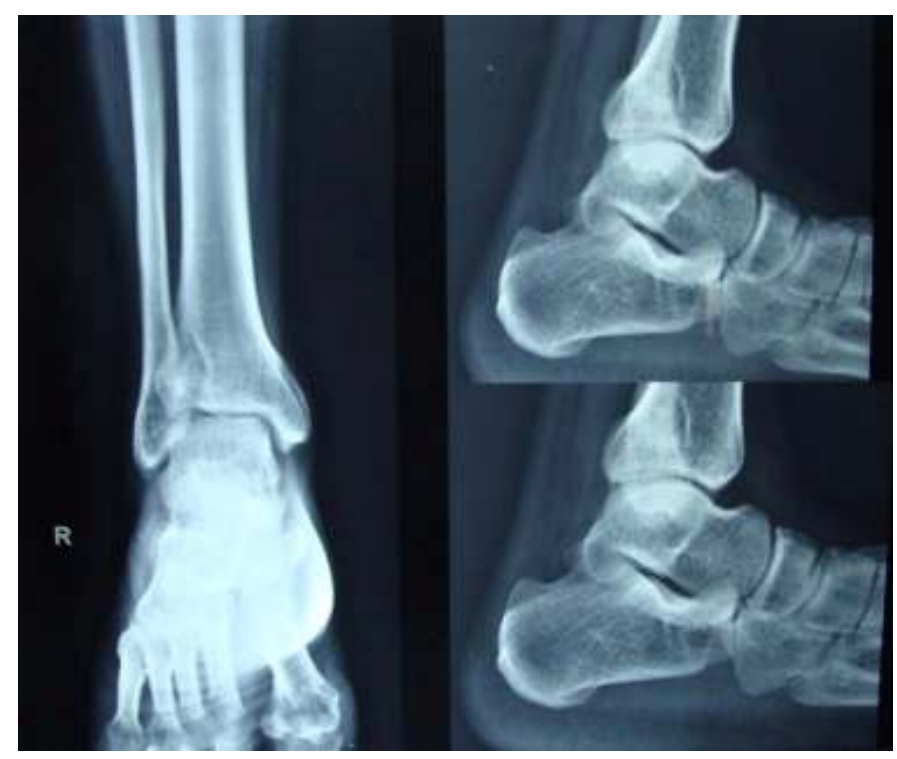

Figure 3 An anteroposterior and lateral digital radiographic views of the right ankle.

The osteotomy site was fixed using a semitubular plate and distal syndesmotic screw was used to fix the syndesmosis. Histological examination showed typical appearance of a benign osteochondroma with no evidence of malignant transformation. The patient had an uneventful recovery with no evidence of recurrence two years after surgery. The ankle range of motion was normal when patient was last evaluated. 


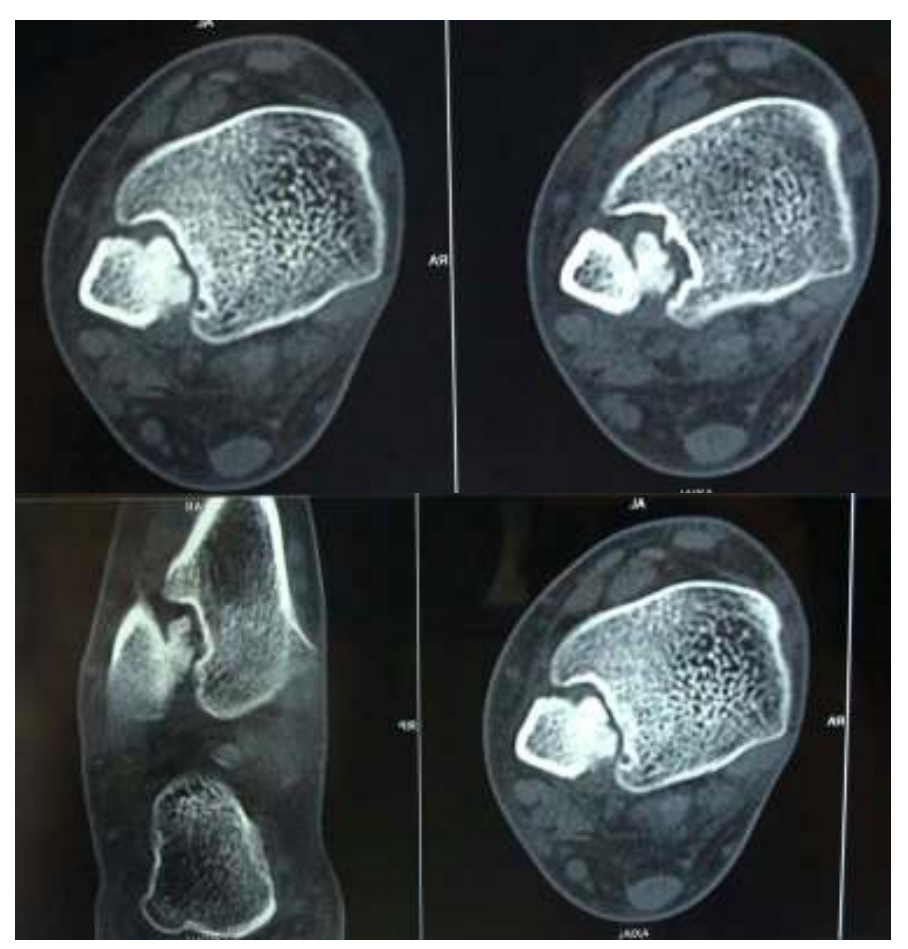

Figure 4 Computed tomography scans of the patient.

\section{Discussion}

Osteochondromas are common benign bone tumors and most often occur in the metaphyseal area of distal femur, proximal tibia, and proximal humerus. ${ }^{6}$ Distal radius, distal tibia, proximal and distal fibula and sometimes flat bones like ilium and scapulae are other areas where osteochondromas can occur. There have been many theories proposed to explain the occurrence of osteochondromas. Virchow's physeal theory ${ }^{7}$, Keith's defect in perichondrial ring ${ }^{8}$, Muller's theory of presence of small nests of cartilage are a few to mention. Current thought is that osteochondroma results because of misdirected growth of a portion of the physeal plate. Osteochondroma may be sessile or pedunculated. The tumor often resembles a cauliflower and is covered by a cartilaginous cap usually 1 to $3 \mathrm{~mm}$ thick. The cartilaginous cap is composed of bland hyaline cartilage with no cellular atypia. Malignant degeneration should be considered if there is an increase in the thickness of cartilage which becomes evident in an adult.

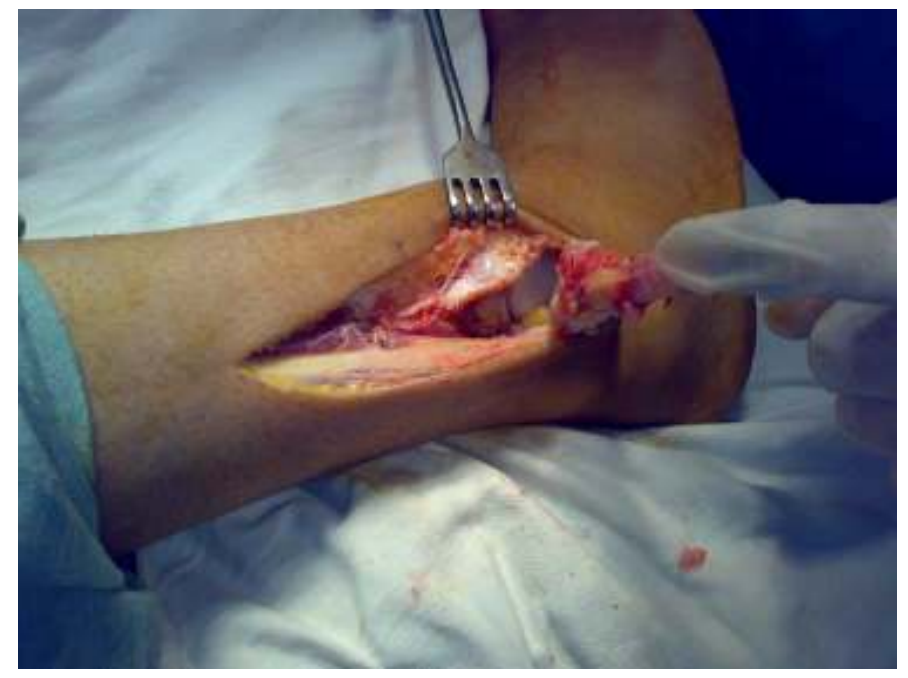

Figure 5 Intra operative photograph after fibular osteotomy showing tumor and pressure effects on tibia.

Osteochondromas are most commonly diagnosed between the ages of 10 to 20 years with a slight male preponderance. Osteochondromas rarely become symptomatic after attainment of skeletal maturity however secondary impingement of soft tissues (tendons, nerves, vessels), fracture through the stalk, pseudo aneurysm formation, infection, ischemic necrosis and malignant transformation may result in appearance of symptoms in adults..$^{10-14}$ After attainment of skeletal maturity there is cessation of growth of most osteochondromas ${ }^{2}$ or a very small amount of growth can still occur after physeal closure. $^{15}$

In the reviewed literature, there are few cases reported which mention osteochondroma arising from distal tibia laterally and invading the interosseous space and producing pressure effects on fibula. ${ }^{3,45}$ We could have used the anterior approach to excise the tumor, but rather a transfibular approach was performed as advised by Gupte, et al. ${ }^{16}$ Although , this approach has been used for a tibial osteochondroma, it proved to be an excellent method of visualizing the tumor for complete excision.(Fig. 5) Again, this may be the first reported case of an osteochondroma arising from the distal fibula invading the interosseous space and producing effects on the tibia. 


\section{Conflict of interest statement}

The authors declare that there are no conflicts of interest

\section{Consent}

Written informed consent was obtained from the patient's guardian for publication of this case report and accompanying images. A copy of the written consent is available for review by the Editor-in-Chief of this journal.

\section{Authors contribution}

AS and MMW designed the study, wrote the manuscript, performed literature review, MAH, IW, $\mathrm{AB}$ and $\mathrm{BAM}$ helped in literature review and drafting the final manuscript. All authors read and approved the final manuscript.

\section{References}

1.Schajowicz F. Tumors and Tumor like lesions of Bone and Joints. 1981, New York, Springer-Verlag. 2.Chrisman OD, Goldenberg RR. Untreated solitary osteochondroma. Report of two cases. JBJS 1968 50A: 508-512. 3.Galasso O, Mariconda M, Milano C. An enlarging distal tibia osteochondroma in the adult patient. JAPMA 2009 99(2): 157161.

4.Danielsson LG, el-Haddad I, Quadros O. Distal tibial osteochondroma deforming the fibula. Acta Orthop Scand. 1990 61(5): 469-470.

5. Spatz DK, Guille JT, Kumar SJ. Distal tibiofibular diastasis secondary to osteochondroma in a child. Clin Orthop Relat Res 1997 (345): 195-197.

6.Essadki B, Moujtahid M, Lamine A, Fikry T, Essadki O, Zryouil B. Solitary osteochondroma of the limbs: clinical review of 76 cases and pathogenic hypothesis [in French]. Acta Orthop Belg 2000 66: 146-153.

7.Virchow R (1891). Ueber multiple exostosen, mit vorlegung von praparaten. Klin Wochenschr 28: 1082-1085.

8.Keith A. Studies on the anatomical changes which accompany certain growth disorders of the human body. J Anat 1920 54:101-106.

9.Muller E. Uber hereditare multiple cartilaginare exostosen and enchondrosen. Beitr Pathol Anat 1913 57: 232
10.Anderson RL, Popowitz L, Li KH. An unusual sarcoma arising in a solitary osteochondroma. JBJS 1969 SIA: 1199-1204. 11. El-Khoury GV, Bassett GS. Symptomatic bursa formation with osteochondromas. AJR Am J Roentgenol 1979 133: 895898.

12. Ferriter P, Hirschy J, Kesseler H, Scott WN. Popliteal pseudoaneurysm. A case report. JBJS 1983 65A: 695-697. 13. Garrison RC, Unni KK, McLeod RA, Pritchard DJ, Dahlin, DC (1982). Chondrosarcoma arising in osteochondroma. Cancer 49: 1890-1897.

14.Unger EC, Gilula LA, Kyriakos M. Case report 430: ischemic necrosis of osteochondroma of tibia. Skel Radiol 1987 16: 416421.

15.Lange RH, Lange TA, Rao BK. Correlative radiographic, scintigraphic, and histological evaluation of exostoses. JBJS 1984 66A: 1454-1459.

16.Gupte CM, Dasgupta R, Beverly MC. The transfibular approach for distal tibial osteochondroma: an alternative technique for excision. J Foot Ankle Surg 2003 42(2): 95-98. 